\title{
The GH receptor exon 3 deleted/full-length polymorphism is associated with central adiposity in the general population
}

\section{Camilla A M Glad', Lena M S Carlsson², Olle Melander ${ }^{3}$, Peter Almgren ${ }^{3}$, Lars Sjöström ${ }^{2}$, Staffan Nilsson ${ }^{4}$, Ingrid Larsson ${ }^{5}$, Per-Arne Svensson ${ }^{2}$ and Gudmundur Johannsson ${ }^{1}$}

Departments of ${ }^{1}$ Endocrinology and ${ }^{2}$ Molecular and Clinical Medicine, Institute of Medicine, The Sahlgrenska Academy, Sahlgrenska University Hospital, University of Gothenburg, Vita Stråket 15, SE-413 45 Gothenburg, Sweden, ${ }^{3}$ Department of Clinical Sciences, Lund University, Malmö, Sweden, ${ }^{4}$ Department of Mathematical Statistics, Chalmers University of Technology, Gothenburg, Sweden and ${ }^{5}$ Department of Endocrinology, Diabetology and Metabolism, Sahlgrenska University Hospital, Gothenburg, Sweden
Correspondence should be addressed to C A M Glad

Email

camilla.glad@medic.gu.se

\begin{abstract}
Objective: To test the hypothesis that the GH receptor (GHR) exon 3 deleted (d3)/full-length (fl) polymorphism influences anthropometry and body composition in the general population.

Design and setting: The Swedish Obese Subjects (SOS) reference study is a cross-sectional population-based study, randomly selected from a population registry. A subgroup of the population-based Malmö Diet and Cancer study (MDC-CC) was used as a replication cohort.

Methods: The SOS reference study comprises 1135 subjects (46.2\% men), with an average age of 49.5 years. The MDC-CC includes 5451 successfully genotyped subjects ( $41.5 \%$ men), with an average age of 57.5 years. GHR d3/fl genotypes were determined using TagSNP rs6873545. Linear regression analyses were used to test for genotype-phenotype associations. Results: In the SOS reference study, subjects homozygous for the d3-GHR weighed $\sim 4 \mathrm{~kg}$ more $(P=0.011)$, and had larger waist-to-hip ratio (WHR, $P=0.036)$, larger waist circumference $(P=0.016)$, and more fat-free mass estimated from total body potassium $(P=0.026)$ than grouped $\mathrm{fl} / \mathrm{d} 3$ and $\mathrm{fl} / \mathrm{fl}$ subjects (d3-recessive genetic model). The association with WHR was replicated in the MDC-CC $(P=0.002)$, but not those with other anthropometric traits.

Conclusions: In this population-based study, the GHR $\mathrm{d} 3 / \mathrm{fl}$ polymorphism was found to be of functional relevance and associated with central adiposity, such that subjects homozygous for the d3-GHR showed an increased abdominal obesity.
\end{abstract}

\section{Introduction}

In higher organisms, traits of body composition and anthropometry (such as body height and body weight) are determined by a complex interplay of environmental and genetic factors. During the course of evolution, efficient parallel systems that monitor and regulate the metabolic state have emerged; systems that are composed of a collection of important proteins that ultimately sets the stage for interindividual variation in energy metabolism. As such, the growth hormone-insulin-like growth factor 1 (GH-IGF1) axis is a major player in the regulation of metabolic traits in humans.

$\mathrm{GH}$ is secreted from the anterior pituitary gland in a pulsatile pattern that is influenced by factors such as age, sex, sleep, feeding, physical activity, and obesity (1). GH is an important stimulator of postnatal longitudinal growth and it has been shown to directly stimulate the cells in the growth plate to induce growth (2). In addition, GH has major effects on fuel metabolism by influencing muscle (c) 2015 European Society of Endocrinology Printed in Great Britain
Published by Bioscientifica Ltd. 
(protein anabolism) and fat (lipolysis), and through regulation of glucose and lipid metabolism (1). In healthy subjects, GH secretion and visceral adipose tissue mass is strongly, and inversely, associated (3). Patients with obesity, particularly abdominal obesity, display a marked decrease in GH secretion (4). When subjects with abdominal obesity are treated with $\mathrm{GH}$, the abdominal fat mass is reduced and the metabolic status is improved (5). Adults with severe GH deficiency (GHD) have abdominal adiposity, increased total body fat mass, and reduced muscle mass that is improved during GH replacement therapy (6), which further emphasizes the pronounced effects of $\mathrm{GH}$ on the regulation of anthropometric traits in humans.

At the molecular level, GH effects are mediated by the $\mathrm{GH}$ receptor (GHR), encoded by the GHR gene located on chromosome 5, region p13.1-p12 $(7,8)$. The GHR is a transmembrane glycoprotein belonging to the type 1 cytokine receptor superfamily $(9,10)$. A 22-amino acid truncated isoform of the GHR protein exists, due to a polymorphism within the GHR gene where the entire exon 3 sequence is missing (8). This genomic deletion is due to an early homologous recombination event and has been passed on through generations (11). The exon 3 deleted (d3)-GHR has been suggested to confer a higher responsiveness to $\mathrm{GH}$ compared with the full-length (fl)GHR (12). Clinical data from GH treatment studies in adult populations have demonstrated conflicting results with reports of both increased (13) and decreased (14) responses to $\mathrm{GH}$ in carriers of the d3-GHR. In children, however, the d3-GHR has been confirmed to confer a larger growth response to $\mathrm{GH}$ in meta-analyses $(15,16)$.

Based on the proposed relation between the d3-GHR and increased GH sensitivity, we aimed to test the hypothesis that carriers of the d3-GHR in the general population would be taller, leaner, and have more fat-free mass (FFM), reflecting a more GH-sensitive phenotype.

\section{Materials and methods}

\section{Subjects and samples}

Ethics statement - Regional ethic review boards at the University of Gothenburg and Lund University approved the studies, and all participants gave informed consent before the examinations.

The Swedish Obese Subjects reference study $\downarrow$ The Swedish Obese Subjects (SOS) reference study includes subjects from the Swedish cities Mölndal and Örebro, randomly selected from a population registry to constitute a reference group to the SOS intervention study, presented elsewhere (17). The study includes 1135 subjects $(46.2 \%$ men), with an average age of $49.5 \pm 7.0$ years and average BMI of $25.2 \pm 3.8 \mathrm{~kg} / \mathrm{m}^{2}$ (18).

All anthropometric measurements were performed with the subjects dressed in underwear, as described by Sjostrom et al. (17). The following circumferences were measured in the recumbent position. Waist circumference was measured at the level midway between the most caudal part of the lateral costal arch and the iliac crest at the end of a normal expiration. Hip circumference was measured at the symphysis-trochanter femoris level. BMI and waist-to-hip ratio (WHR) were calculated. Body weight was compartmentalized into FFM and body fat (BF) using the total body potassium (TBK) method. The TBK measurements were performed in the whole-body counter system II, at the Department of Radiation Physics at the Sahlgrenska University Hospital, Göteborg, Sweden. FFM (kg) was calculated from the TBK measurements using the constants 64.7 for men (19) and 62.0 for women (20). $\mathrm{BF}(\mathrm{kg})$ was then calculated as the FFM subtracted from the body weight. Blood samples were obtained after an overnight fast. IGF1 was measured in serum by a hydrochloric acid-ethanol extraction RIA using authentic IGF1 for labeling (Nichols Institute Diagnostics, San Juan Capistrano, CA, USA), with an inter-assay coefficient of variation of 2.5 and $4.2 \%$ at serum concentrations of 125 and $345 \mu \mathrm{g} / 1$ respectively.

The Malmö Diet and Cancer study - The Malmö Diet and Cancer study (MDC-CC) is a prospective populationbased cohort study including 28449 subjects recruited during the period of 1991-1996 (21). Subjects aged 45-69 years, living in the city of Malmö, Sweden were eligible for participation. Between November 1991 and February 1994, every other enrolled subject was also invited to take part in a substudy of the epidemiology of carotid artery disease (22). This MDC-CC cohort consists of 6103 subjects, 5540 of whom also agreed to have blood collected under standardized fasting conditions; 5451 subjects were successfully genotyped (41.5\% men; average age $57.5 \pm 5.9$ years, average BMI $25.8 \pm 4.0 \mathrm{~kg} / \mathrm{m}^{2}$ ). Standardized anthropometrics measurements were performed. Waist circumference $(\mathrm{cm})$ was measured in the standing position midway between the lower rib margin and the ileac crest.

\section{DNA isolation and genotyping}

The SOS reference study $\downarrow$ Genomic DNA was isolated using the Mag Maxi Plus Kit (AGOWA GmbH, Berlin, 
Germany) and a semi-automated magnetic bead technique on a Microlab Star instrument (Hamilton Robotics, Reno, NV, USA). Genotyping was performed using TaqMan SNP genotyping of the GHR d3/fl TagSNP rs6873545, which was validated previously (23). Briefly, $10 \mathrm{ng}$ genomic DNA was added to a reaction mix containing $1 \times$ TaqMan Genotyping PCR Master Mix (Applied Biosystems) and an rs6873545-specific genotyping assay (C_28966089_10; Applied Biosystems). All reactions were carried out in $5 \mu 1$ reaction volumes on 384-well plates (Applied Biosystems). PCR amplification and allele detection were carried out in an ABI Prism 7900HT Sequence Detection System instrument (Applied Biosystems).

The MDC-CC $\triangleright$ DNA was extracted from whole-blood samples using Qiagen Maxipreps (Qiagen). SNP rs6873545 was genotyped using the Illumina Human OmniExpressExome BeadChip v1.0.

\section{Statistical analyses}

Linear regression analyses were used to investigate the impact of the $G H R \mathrm{~d} 3 / \mathrm{fl}$ polymorphism (in a d3-recessive model) on anthropometric measurements, body composition, and serum IGF1 concentrations using sex and age as other predictors. Deviations from the Hardy-Weinberg equilibrium (HWE) were tested by the goodness-of-fit $\chi^{2}$ test. The Statistical Software R (version 2.12.1) was used for the statistical analyses.

\section{Results}

\section{GHR $\mathrm{d} 3 / \mathrm{fl}$ genotyping}

Genotyping success rate was 99.1\% (98.4\%) and the frequency of the d3-GHR was $24.0 \%$ (fl/fl $57.6(58.1) \%$, fl/d3 36.8 (36.6)\%, and d3/d3 5.6 (5.4)\% in the SOS reference and MDC-CC studies respectively (MDC-CC data presented within brackets)). No deviations from the HWE were found ( $\chi^{2}$ test, $P=0.8$ and 0.4 respectively).

\section{Association analyses}

The SOS reference study and the MDC-CC both contain unselected subjects from the general Swedish population, and hence these studies are unmatched for clinical parameters. Waist circumference and WHR tended to be higher in the SOS reference study, which also contained more men, than the MDC-CC. By contrast, both systolic and diastolic blood pressure tended to be higher in the
MDC-CC, and the subjects were also older than those in the SOS reference study. General baseline characteristics of the subjects are presented in Table 1 . Clinical characteristics of the study subjects when divided into $G H R \mathrm{~d} 3 / \mathrm{fl}$ genotype groups and results from the linear regression analyses, adjusted for sex and age, are shown in Table 2.

The SOS reference study $\downarrow$ Homozygosity for the d3-GHR was associated with higher WHR $(P=0.036)$, waist circumference $(P=0.016)$, body weight $(P=0.011)$, BMI $(P=0.049)$, and FFM estimated from TBK $(P=0.026)$. No associations were found between $G H R \mathrm{~d} 3 / \mathrm{fl}$ genotype and serum IGF1 levels $(P=0.4)$, body height $(P=0.2)$, fasting glucose $(P=0.5)$, or plasma insulin $(P=0.9)$ levels.

The MDC-CC $>$ In the MDC-CC, homozygosity for the d3-GHR was associated with a significantly higher WHR $(P=0.002)$. Genotype was not associated with waist circumference $(P=0.1)$, body weight $(P=0.6)$, body height $(P=0.2)$, fasting glucose $(P=0.5)$, or plasma insulin $(P=0.9)$ levels.

\section{Discussion}

In this study, we demonstrate for the first time an association of the $G H R \mathrm{~d} 3 / \mathrm{fl}$ polymorphism with central adiposity in two independent populations of Swedish middle-aged subjects. Specifically, subjects homozygous for the d3-GHR had larger WHR.

Based on previous findings, which suggest that subjects carrying the d3-GHR are more sensitive to $\mathrm{GH}$,

Table 1 Clinical characteristics of the subjects in the SOS reference and the MDC-CC studies. Values are expressed as means \pm s.D.

\begin{tabular}{|c|c|c|}
\hline Clinical variables & SOS reference study & MDC-CC \\
\hline$n$ & 1135 & 5451 \\
\hline Sex (men, \%) & 46.2 & 41.5 \\
\hline Age (years) & $49.5 \pm 7.0$ & $57.5 \pm 5.9$ \\
\hline Body height (m) & $1.7 \pm 0.1$ & $1.7 \pm 0.1$ \\
\hline Body weight (kg) & $75.1 \pm 14.2$ & $73.7 \pm 13.7$ \\
\hline BMI $\left(\mathrm{kg} / \mathrm{m}^{2}\right)$ & $25.2 \pm 3.8$ & $25.8 \pm 4.0$ \\
\hline Waist $(\mathrm{cm})$ & $87.9 \pm 11.2$ & $84.1 \pm 13.0$ \\
\hline WHR & $0.88 \pm 0.08$ & $0.85 \pm 0.09$ \\
\hline SBP $(\mathrm{mmHg})$ & $125.2 \pm 19.1$ & $141.2 \pm 18.9$ \\
\hline $\mathrm{DBP}(\mathrm{mmHg})$ & $76.6 \pm 11.3$ & $86.9 \pm 9.4$ \\
\hline Fat-free mass ${ }^{\mathrm{a}}(\mathrm{kg})$ & $55.7 \pm 11.5$ & NA \\
\hline Body fat ${ }^{a}(\mathrm{~kg})$ & $18.7 \pm 8.6$ & NA \\
\hline IGF1 ( $\mu \mathrm{g} / \mathrm{l})$ & $207.0 \pm 64.9$ & NA \\
\hline
\end{tabular}

WHR, waist-to-hip ratio; SBP, systolic blood pressure; DBP, diastolic blood pressure.

${ }^{\mathrm{a}}$ Estimated from total body potassium (TBK) measurements. 
Table 2 Clinical characteristics of the study subjects when divided into genotype groups, and results (sex- and age-adjusted effect sizes and $P$ values) from the regression analyses in the SOS reference and the MDC-CC studies, using a d3-GHR recessive model of inheritance.

\begin{tabular}{|c|c|c|c|c|c|c|c|c|c|c|}
\hline \multirow[b]{2}{*}{ Clinical variables } & \multicolumn{5}{|c|}{ SOS reference study } & \multicolumn{5}{|c|}{ MDC-CC } \\
\hline & $\mathrm{fl} / \mathrm{fl}$ & $\mathrm{fl} / \mathrm{d} 3$ & $\mathrm{~d} 3 / \mathrm{d} 3$ & $\beta$ & $P$ & $\mathrm{fl} / \mathrm{fl}$ & $\mathrm{fl} / \mathrm{d} 3$ & $\mathrm{~d} 3 / \mathrm{d} 3$ & $\beta$ & $P$ \\
\hline Body height $(\mathrm{cm})$ & 172.3 & 171.7 & 173.6 & 1.0 & 0.175 & 168.8 & 169.2 & 169.0 & -0.5 & 0.2 \\
\hline Body weight $(\mathrm{kg})$ & 75.0 & 74.5 & 78.8 & 3.9 & 0.011 & 73.3 & 74.2 & 74.6 & 0.3 & 0.6 \\
\hline BMI $\left(k g / m^{2}\right)$ & 25.2 & 25.2 & 26.0 & 1.0 & 0.049 & 25.7 & 26.0 & 26.1 & 0.2 & 0.3 \\
\hline Waist $(\mathrm{cm})$ & 87.8 & 87.4 & 90.7 & 3.2 & 0.016 & 83.7 & 84.5 & 85.7 & 0.9 & 0.1 \\
\hline WHR & 0.88 & 0.88 & 0.90 & 0.02 & 0.036 & 0.85 & 0.85 & 0.87 & 0.01 & 0.002 \\
\hline FFM $(\mathrm{kg})^{\mathrm{a}}$ & 56.2 & 54.4 & 58.7 & 2.2 & 0.021 & NA & NA & NA & NA & NA \\
\hline Body fat $(\mathrm{kg})^{\mathrm{a}}$ & 18.4 & 19.1 & 20.2 & 2.2 & 0.065 & NA & NA & NA & NA & NA \\
\hline IGF1 $(\mu \mathrm{g} / \mathrm{l})$ & 207.1 & 206.5 & 203.8 & -6.7 & 0.413 & NA & NA & NA & NA & NA \\
\hline
\end{tabular}

WHR, waist-to-hip ratio. Significant $P$ values are highlighted in bold and close-to-significant $(P<0.1)$ are shown in italics. $\beta$ corresponds to average effect size. Positive effects size corresponds to a larger value in d3-GHR homozygotes, compared with the grouped fl/d3 and fl/fl subjects. Average (mean) observed values for selected clinical variables are shown.

astimated from total body potassium (TBK) measurements.

we anticipated that d3-GHR carriers should be taller, have increased FFM and less body fat, and, in particular, reduced abdominal fat. By contrast, we found a metabolically adverse profile in subjects homozygous for the d3-GHR. However, the data suggesting increased GH sensitivity in carriers of the d3-GHR are based on treatment response to exogenous $\mathrm{GH}$ in patients with GHD, who exhibit severe disturbances in the normal regulation of the hypothalamic-pituitary axis $(15,16)$. Thus, our findings may reflect the complex relationship among GH sensitivity, GH secretion, and other adaptive metabolic mechanisms that occur throughout life in subjects with a normally functioning GH-IGF1 axis.

$\mathrm{GH}$ efficiently induces lipolysis. The lipolytic response to $\mathrm{GH}$ is more marked in visceral fat mass, which is demonstrated by a marked decrease in abdominal fat mass in response to GH treatment (24). Inversely, abdominal adiposity, particularly visceral adipose tissue mass, is a stronger negative determinant of GH secretion than age, sex, or BMI $(3,25,26)$. In obesity, both spontaneous $(27$, 28) and stimulated (29) GH secretion is blunted. Specifically, the amount of GH secreted per burst is decreased, although burst frequency is unaffected $(27,28)$. The metabolic clearance rate of $\mathrm{GH}$ is accelerated in individuals with obesity (28), further decreasing the amount of bioavailable GH. Low endogenous $\mathrm{GH}$ secretion in the obese state has been associated with increased cardiovascular risk factors $(30,31,32,33)$, although a cause-and-effect relationship is yet to be established.

In the SOS reference study, homozygotes of the d3GHR had larger FFM when compared with grouped fl/fl and $\mathrm{d} 3 / \mathrm{fl}$ subjects, possibly indicating a higher $\mathrm{GH}$ sensitivity in muscle in this genotype group. It should be noted, however, that the increased FFM in d3-GHR homozygotes could also be secondary to the higher body mass observed in these subjects, as subjects who weigh heavier generally require a larger muscle mass. Unfortunately, FFM was not measured in the replication cohort, and thus this finding could not be verified.

WHR is a strong predictor of cardiovascular risk (34). We found that subjects homozygous for the d3-GHR had larger WHR in two independent cohorts of adult Swedes. The d3-GHR and fl-GHR may have differential properties. Previously, the d3-GHR was shown to be associated with WHR in a cohort of healthy Chinese women and overrepresented among subjects with polycystic ovary syndrome (35). Moreover, it has been shown that subjects with type 2 diabetes mellitus carrying the d3-GHR had a larger BMI, and a more adverse metabolic profile (36). In addition, in a study on Chinese children, the d3-GHR was over-represented among obese children (37). Although these studies do comprise strikingly different cohorts when compared with ours, these recent findings point in the same direction. The d3-GHR appears to be associated with a more obese, and specifically a more abdominally obese, phenotype than the fl-GHR. The implications of these novel data remain yet to be further elucidated, and more mechanistic studies are warranted. Clearly, most previous studies have been carried out in small, selected cohorts of patients with limited power to fully detect the possible significance of d3-GHR homozygosity. Furthermore, the treatment response to GHRT is in itself confounded by the subsequent GH dose titration regimen that may mask or skew the possible effects of this genetic variant. In our previous study on adult GHD subjects, fl-GHR homozygotes did respond better to GHRT in terms of the very rapid (1 week) percentage increase in 
serum IGF1 levels (14). Hence, new data are emerging that challenge the concept of an increased GH sensitivity in d3-GHR carriers.

To our knowledge, this is the first study on the GHR $\mathrm{d} 3 / \mathrm{fl}$ polymorphism in relation to anthropometry and body composition in large cohorts of randomly selected subjects. Our findings support the notion that the GHR $\mathrm{d} 3 / \mathrm{fl}$ polymorphism is of functional relevance, and indicate an adverse influence of the d3-GHR on the regulation of central adiposity.

\section{Declaration of interest}

The authors declare that there is no conflict of interest that could be perceived as prejudicing the impartiality of the research reported.

\section{Funding}

This study was supported by grants from the Swedish Research Council (K201055X-11285-13), the Swedish Foundation for Strategic Research to Sahlgrenska Center for Cardiovascular and Metabolic Research, the Swedish federal government under the LUA/ALF agreement, the University of Gothenburg, the European Research Council (StG-282255), the Swedish Medical Research Council, the Swedish Heart and Lung Foundation, the Medical Faculty of Lund University, Skåne University Hospital, and the Novo Nordisk Foundation.

\section{Acknowledgements}

The authors would like to extend their gratitude to Gerd Bergmark at the Department of Molecular and Clinical Medicine, the University of Gothenburg, for kindly providing practical assistance and also to the staff at the Obesity Unit, the Sahlgrenska University Hospital, for their committed work to perform this study.

\section{References}

1 Giustina A \& Veldhuis JD. Pathophysiology of the neuroregulation of growth hormone secretion in experimental animals and the human. Endocrine Reviews 199819 717-797. (doi:10.1210/edrv.19.6.0353)

2 Isaksson OG, Jansson JO \& Gause IA. Growth hormone stimulates longitudinal bone growth directly. Science 1982216 1237-1239. (doi:10.1126/science.7079756)

3 Vahl N, Jorgensen JO, Skjaerbaek C, Veldhuis JD, Orskov H \& Christiansen JS. Abdominal adiposity rather than age and sex predicts mass and regularity of GH secretion in healthy adults. American Journal of Physiology 1997272 E1108-E1116.

4 Franco C, Bengtsson BA \& Johannsson G. The GH/IGF-1 axis in obesity: physiological and pathological aspects. Metabolic Syndrome and Related Disorders 20064 51-56. (doi:10.1089/met.2006.4.51)

5 Johannsson G, Marin P, Lonn L, Ottosson M, Stenlof K, Bjorntorp P, Sjostrom L \& Bengtsson BA. Growth hormone treatment of abdominally obese men reduces abdominal fat mass, improves glucose and lipoprotein metabolism, and reduces diastolic blood pressure. Journal of Clinical Endocrinology and Metabolism 199782 727-734. (doi:10.1210/ jcem.82.3.3809)

6 Johannsson G. Management of adult growth hormone deficiency. Endocrinology and Metabolism Clinics of North America 200736 203-220. (doi:10.1016/j.ecl.2006.11.012)
7 Barton DE, Foellmer BE, Wood WI \& Francke U. Chromosome mapping of the growth hormone receptor gene in man and mouse. Cytogenetics and Cell Genetics 198950 137-141. (doi:10.1159/000132743)

8 Godowski PJ, Leung DW, Meacham LR, Galgani JP, Hellmiss R, Keret R, Rotwein PS, Parks JS, Laron Z \& Wood WI. Characterization of the human growth hormone receptor gene and demonstration of a partial gene deletion in two patients with Laron-type dwarfism. PNAS 198986 8083-8087. (doi:10.1073/pnas.86.20.8083)

9 Bazan JF. Structural design and molecular evolution of a cytokine receptor superfamily. PNAS 199087 6934-6938. (doi:10.1073/pnas.87. 18.6934)

10 de Vos AM, Ultsch M \& Kossiakoff AA. Human growth hormone and extracellular domain of its receptor: crystal structure of the complex. Science 1992255 306-312. (doi:10.1126/science.1549776)

11 Pantel J, Machinis K, Sobrier ML, Duquesnoy P, Goossens M \& Amselem S. Species-specific alternative splice mimicry at the growth hormone receptor locus revealed by the lineage of retroelements during primate evolution. Journal of Biological Chemistry 2000275 18664-18669. (doi:10.1074/jbc.M001615200)

12 Dos Santos C, Essioux L, Teinturier C, Tauber M, Goffin V \& Bougneres P. A common polymorphism of the growth hormone receptor is associated with increased responsiveness to growth hormone. Nature Genetics 200436 720-724. (doi:10.1038/ng1379)

13 van der Klaauw AA, van der Straaten T, Baak-Pablo R, Biermasz NR, Guchelaar HJ, Pereira AM, Smit JW \& Romijn JA. Influence of the d3growth hormone $(\mathrm{GH})$ receptor isoform on short-term and long-term treatment response to $\mathrm{GH}$ replacement in GH-deficient adults. Journal of Clinical Endocrinology and Metabolism 200893 2828-2834. (doi:10.1210/jc.2007-2728)

14 Glad CA, Barbosa EJ, Filipsson Nystrom H, Carlsson LM, Nilsson S, Nilsson AG, Svensson PA \& Johannsson G. SNPs within the GH-signaling pathway are associated with the early IGF1 response to GH replacement therapy in GHD adults. European Journal of Endocrinology 2014170 101-107. (doi:10.1530/EJE-13-0685)

15 Renehan AG, Solomon M, Zwahlen M, Morjaria R, Whatmore A, Audi L, Binder G, Blum W, Bougneres P, Santos CD et al. Growth hormone receptor polymorphism and growth hormone therapy response in children: a Bayesian meta-analysis. American Journal of Epidemiology 2012175 867-877. (doi:10.1093/aje/kwr408)

16 Wassenaar MJ, Dekkers OM, Pereira AM, Wit JM, Smit JW, Biermasz NR $\&$ Romijn JA. Impact of the exon 3-deleted growth hormone $(\mathrm{GH})$ receptor polymorphism on baseline height and the growth response to recombinant human GH therapy in GH-deficient (GHD) and non-GHD children with short stature: a systematic review and meta-analysis. Journal of Clinical Endocrinology and Metabolism 200994 3721-3730. (doi:10.1210/jc.2009-0425)

17 Sjostrom L, Larsson B, Backman L, Bengtsson C, Bouchard C, Dahlgren S, Hallgren P, Jonsson E, Karlsson J, Lapidus L et al. Swedish obese subjects (SOS). Recruitment for an intervention study and a selected description of the obese state. International Journal of Obesity and Related Metabolic Disorders 199216 465-479.

18 Larsson I, Berteus Forslund H, Lindroos AK, Lissner L, Naslund I, Peltonen M \& Sjostrom L. Body composition in the SOS (Swedish Obese Subjects) reference study. International Journal of Obesity and Related Metabolic Disorders 200428 1317-1324. (doi:10.1038/sj.ijo.0802732)

19 Kvist H, Chowdhury B, Sjostrom L, Tylen U \& Cederblad A. Adipose tissue volume determination in males by computed tomography and 40K. International Journal of Obesity 198812 249-266.

20 Sjostrom L, Kvist H, Cederblad A \& Tylen U. Determination of total adipose tissue and body fat in women by computed tomography, 40K, and tritium. American Journal of Physiology 1986250 E736-E745.

21 Berglund G, Elmstahl S, Janzon L \& Larsson SA. The Malmo Diet and Cancer Study. Design and feasibility. Journal of Internal Medicine 1993 233 45-51. (doi:10.1111/j.1365-2796.1993.tb00647.x)

22 Rosvall M, Janzon L, Berglund G, Engstrom G \& Hedblad B. Incident coronary events and case fatality in relation to common carotid 
intima-media thickness. Journal of Internal Medicine 2005257 430-437. (doi:10.1111/j.1365-2796.2005.01485.x)

23 Glad CA, Johannsson G, Carlsson LM \& Svensson PA. Rapid and high throughput genotyping of the growth hormone receptor exon 3 deleted/full-length polymorphism using a tagSNP. Growth Hormone \& IGF Research 201020 270-273. (doi:10.1016/j.ghir.2010.02.004)

24 Bengtsson BA, Eden S, Lonn L, Kvist H, Stokland A, Lindstedt G, Bosaeus I, Tolli J, Sjostrom L \& Isaksson OG. Treatment of adults with growth hormone (GH) deficiency with recombinant human GH. Journal of Clinical Endocrinology and Metabolism 199376 309-317. (doi:10.1210/jcem.76.2.8432773)

25 Clasey JL, Weltman A, Patrie J, Weltman JY, Pezzoli S, Bouchard C, Thorner MO \& Hartman ML. Abdominal visceral fat and fasting insulin are important predictors of 24 -hour GH release independent of age, gender, and other physiological factors. Journal of Clinical Endocrinology and Metabolism 200186 3845-3852. (doi:10.1210/jcem.86.8.7731)

26 Vahl N, Jorgensen JO, Jurik AG \& Christiansen JS. Abdominal adiposity and physical fitness are major determinants of the age associated decline in stimulated GH secretion in healthy adults. Journal of Clinical Endocrinology and Metabolism 199681 2209-2215. (doi:10.1210/jcem. 81.6.8964853)

27 Iranmanesh A, Lizarralde G \& Veldhuis JD. Age and relative adiposity are specific negative determinants of the frequency and amplitude of growth hormone $(\mathrm{GH})$ secretory bursts and the half-life of endogenous GH in healthy men. Journal of Clinical Endocrinology and Metabolism 199173 1081-1088. (doi:10.1210/jcem-73-5-1081)

28 Veldhuis JD, Iranmanesh A, Ho KK, Waters MJ, Johnson ML \& Lizarralde G. Dual defects in pulsatile growth hormone secretion and clearance subserve the hyposomatotropism of obesity in man. Journal of Clinical Endocrinology and Metabolism 199172 51-59. (doi:10.1210/jcem-72-1-51)

29 Williams T, Berelowitz M, Joffe SN, Thorner MO, Rivier J, Vale W \& Frohman LA. Impaired growth hormone responses to growth hormonereleasing factor in obesity. A pituitary defect reversed with weight reduction. New England Journal of Medicine 1984311 1403-1407. (doi:10.1056/NEJM198411293112203)
30 Makimura H, Stanley T, Mun D, Chen C, Wei J, Connelly JM, Hemphill LC \& Grinspoon SK. Reduced growth hormone secretion is associated with increased carotid intima-media thickness in obesity. Journal of Clinical Endocrinology and Metabolism 200994 5131-5138. (doi:10.1210/jc.2009-1295)

31 Miller KK, Biller BM, Lipman JG, Bradwin G, Rifai N \& Klibanski A. Truncal adiposity, relative growth hormone deficiency, and cardiovascular risk. Journal of Clinical Endocrinology and Metabolism 200590 768-774. (doi:10.1210/jc.2004-0894)

32 Utz AL, Yamamoto A, Hemphill L \& Miller KK. Growth hormone deficiency by growth hormone releasing hormone-arginine testing criteria predicts increased cardiovascular risk markers in normal young overweight and obese women. Journal of Clinical Endocrinology and Metabolism 200893 2507-2514. (doi:10.1210/jc.2008-0169)

33 Weltman A, Despres JP, Clasey JL, Weltman JY, Wideman L, Kanaley J, Patrie J, Bergeron J, Thorner MO, Bouchard C et al. Impact of abdominal visceral fat, growth hormone, fitness, and insulin on lipids and lipoproteins in older adults. Metabolism 200352 73-80. (doi:10.1053/meta.2003.50007)

34 Goh LG, Dhaliwal SS, Welborn TA, Lee AH \& Della PR. Anthropometric measurements of general and central obesity and the prediction of cardiovascular disease risk in women: a cross-sectional study. BMJ Open 20144 e004138. (doi:10.1136/bmjopen-2013-004138)

35 Shen Y, Wang L, Zhao Y, You L, Geng L, Gu HF \& Chen ZJ. Evaluation of the association between GHR exon 3 polymorphism and polycystic ovary syndrome among Han Chinese women. Growth Hormone \& IGF Research 201121 248-251. (doi:10.1016/j.ghir.2011.07.002)

36 Strawbridge RJ, Karvestedt L, Li C, Efendic S, Ostenson CG, Gu HF \& Brismar K. GHR exon 3 polymorphism: association with type 2 diabetes mellitus and metabolic disorder. Growth Hormone \& IGF Research 2007 17 392-398. (doi:10.1016/j.ghir.2007.04.005)

37 Gao L, Zheng Z, Cao L, Shen S, Yang Y, Zhao Z, Zhi D, Cheng R, Pei Z, Yongfu $Y$ et al. The growth hormone receptor (GHR) exon 3 polymorphism and its correlation with metabolic profiles in obese Chinese children. Pediatric Diabetes 201112 429-434. (doi:10.1111/ j.1399-5448.2010.00747.x)

Received 25 August 2014

Revised version received 30 October 2014

Accepted 11 November 2014 